\title{
Functionalized D-form self-assembling peptide hydrogels for bone regeneration
}

\author{
This article was published in the following Dove Press journal: \\ Drug Design, Development and Therapy \\ II April 2016 \\ Number of times this article has been viewed
}

Bin He'
Yunsheng Ou'
Ao Zhou'
Shuo Chen'
Weikang Zhao'
Jinqiu Zhao'
Hong Li'
Yong Zhu'
Zenghui Zhao'
Dianming Jiang'
'Department of Orthopedics,
'Department of Infectious Diseases,
The First Affiliated Hospital of
Chongqing Medical University,
Chongqing, People's Republic of
China; '3chool of Physical Science
and Technology, Sichuan University,
Chengdu, People's Republic of China

Correspondence: Dianming Jiang Department of Orthopedics, The First Affiliated Hospital of Chongqing Medical University, Number I Yi Xue Yuan Road, Yuzhong District, Chongqing 4000I6, People's Republic of China

Tel +86 $238901 \quad 1212$

$\mathrm{Fax}+862389011212$

Email jdm571026@vip.163.com

\begin{abstract}
Bone defects are very common in orthopedics, and there is great need to develop suitable bone grafts for transplantation in vivo. However, current bone grafts still encounter some limitations, including limited availability, immune rejection, poor osteoinduction and osteoconduction, poor biocompatibility and degradation properties, etc. Self-assembling peptide nanofiber scaffolds have emerged as an important substrate for cell culture and bone regeneration. We report on the structural features (eg, Congo red staining, circular dichroism spectroscopy, transmission electron microscopy, and rheometry assays) and osteogenic ability of D-RADA16-RGD peptide hydrogels (with or without basic fibroblast growth factor) due to the better stability of peptide bonds formed by these peptides compared with those formed by L-form peptides, and use them to fill the femoral condyle defect of Sprague Dawley rat model. The bone morphology change, two-dimensional reconstructions using microcomputed tomography, quantification of the microcomputed tomography analyses as well as histological analyses have demonstrated that RGD-modified D-form peptide scaffolds are able to enhance extensive bone regeneration.
\end{abstract}

Keywords: bone defect, functionalized D-form self-assembling peptide, D-RADA16-RGD, peptide hydrogel, bone regeneration

\section{Introduction}

Trauma, infection, and tumor resection are regarded as the three main factors causing bone defects, ${ }^{1-3}$ and especially the large bone defects and load-bearing bone defects have a high risk of nonunions and seriously affect the quality of life of patients. Although bone tissues have some regenerative ability, the healing of the large bone defects and load-bearing bone defects require bone grafts to provide mechanical support and induce bone induction as well as conduction. ${ }^{4,5}$ It is widely accepted that with good osteogenic, osteoinductive, and osteoconductive ability, autologous grafts (eg, iliac crest autologous graft) remain the gold standard for bone transplantation. ${ }^{6}$ However, they have some limitations, including the limited availability, pain, donor site morbidity, and the mismatch between harvested bone grafts as well as defect sites. $^{7,8}$ Allogeneic bone grafts (eg, demineralized bone matrix [DBM]) serve as an alternative to repair bone defects and are limited by the suboptimal osteoactivity when compared with autologous grafts, the risk of disease transmission, and immune rejection. ${ }^{1}$ As to synthetic bone repair material scaffolds, they are mainly divided into polymers, bioceramics, metal materials, bioglass, and composite materials..$^{3,9}$ However, there are still some drawbacks (eg, low osteoinductivity and osteoconductivity, the difficulty in degradation or even nondegradation) for their application in bone regeneration. ${ }^{9,10}$ 
Many previous studies have demonstrated that ionic self-complementary peptide-formed nanofiber scaffolds hold some promise in repairing damaged tissues or organs, including bone, ${ }^{3,11}$ cartilage, ${ }^{12,13}$ nerve, ${ }^{14,15}$ heart, ${ }^{16,17}$ as well as in wound healing. ${ }^{18,19}$ The principle of molecular self-assembly guides the ionic self-complementary peptides to self-assemble into three-dimensional (3D) entangled nanofiber hydrogel scaffolds, which are analogous to those found in natural extracellular matrix (ECM). ${ }^{12}$ They contain extremely high water content, more than $99 \%$ in water $\left(5-10 \mathrm{mg} / \mathrm{mL}\right.$, w/v), ${ }^{20}$ and their microenvironment significantly facilitates cell infiltration and retention, the delivery of oxygen and soluble signal molecules, as well as waste product removal. ${ }^{21,22}$

More recently, D-form peptide hydrogel scaffolds have been found to form stable 3D structures and perform some role in hemostasis, cell culture, and wound healing. ${ }^{22}$ To investigate the potential of $\mathrm{D}$-form peptide nanofibers in bone regeneration, we designed and developed D-RADA16-RGD peptides to repair the bone defects of the femoral condyle of Sprague Dawley (SD) rats. Previous studies have reported that $\mathrm{RGD}^{23}$ and $\mathrm{IKVAV}^{24}$ were used to modify peptide-based biomaterial scaffolds. Especially, the tripeptide sequence RGD found in fibronectin and other ECM proteins was capable of enhancing cell differentiation and migration through binding to $\alpha 5 \beta 1$ integrin receptor. ${ }^{25}$ For instance, low RGD concentrations were found to promote the maintenance of chondrocyte number and phenotype, and the generation of ECM contents. ${ }^{26} \mathrm{With}$ the increased similarity to functional structures of fibronectin, peptide PHSRNG6RGD consisting of peptide RGD and PHSRN can significantly induce better cell binding. ${ }^{27}$

In addition, RADA16-I peptide scaffolds are capable of controlled release of various functional proteins, including basic fibroblast growth factor (bFGF), vascular endothelial growth factor, brain-derived neurotrophic factor, lysozyme, trypsin inhibitor, bovine serum albumin, and immunoglobulin G. Further studies demonstrated that through the secondary and tertiary structure analyses and biological assays, these released functional proteins can maintain their original protein conformation and functionality. ${ }^{21,28} \mathrm{bFGF}$ is well known as an important angiogenic factor with favorable influence on migration, proliferation, and differentiation of various cells, including vascular cells and osteoblasts. This angiogenic growth factor significantly stimulates neovascularization at early stages of wound healing and further allows for mesenchymal stem cells transport as well as the supply of oxygen and nutrients, thus holding great promise in promoting the healing of bone defects. ${ }^{29,30}$ One study demonstrated that the released bFGF from peptide hydrogels resulted in remarkable angiogenesis in the subcutaneous tissue of mice. ${ }^{31}$

In this work, the functional motif RGD was applied to modify peptide D-RADA16 for designing and fabricating peptide D-RADA16-RGD. The secondary structure, microstructural feature, rheology, etc, of peptide D-RADA16-RGD was performed. Also, to explore its potential of releasing growth factors, angiogenic growth factor bFGF is incorporated into these peptide hydrogel scaffolds. Furthermore, self-assembling peptide D-RADA16-RGD hydrogels (with or without bFGF) are applied to repair the bone defects of SD rat femoral condyle, with the aim of evaluating the osteogenic ability of D-RADA16-RGD hydrogels.

\section{Materials and methods Peptides synthesis and purification}

The peptide D-RADA16-RGD sequence containing all D-amino acids is Ac-(Arg-Ala-Asp-Ala-Arg-Ala-Asp-Ala) ${ }_{2}$ Gly-Gly-Arg-Gly-Asp-Ser-CONH${ }_{2}$. These peptides were commercially custom synthesized by solid-phase peptide synthesis (Shanghai Biotech Bioscience and Technology Co, Ltd, Shanghai, People's Republic of China). The peptides were acetylated and amidated at the $\mathrm{N}$-terminus and C-terminus, respectively. These were then purified by high-performance liquid chromatography and characterized by mass spectroscopy. The purity of the D-RADA16-RGD was $98.58 \%$.

\section{Peptide membrane preparations}

The peptide membrane structures were prepared as follows: $5-10 \mu \mathrm{L}$ of the stock solution of peptide D-RADA16-RGD $(5 \mathrm{mg} / \mathrm{mL})$ was added to $1.0 \mathrm{~mL}$ of phosphate-buffered saline (PBS, pH 7.4) with $0.0005 \%$ Congo red on a glass slide.

\section{Circular dichroism spectroscopy}

The peptide samples consisting of $1.0 \mathrm{mg} / \mathrm{mL}$ peptide aqueous stock were dissolved and adjusted to $100 \mu \mathrm{M}$ using $20 \mathrm{mM} \mathrm{CaCl}_{2}$. Measurements were carried out on a circular dichroism (CD) spectrometer (J-810, JASCO Corporation, Tokyo, Japan) at different temperatures, $25^{\circ} \mathrm{C}, 37^{\circ} \mathrm{C}$, and $60^{\circ} \mathrm{C}$. The analysis was done using a $\mathrm{CD}$ cuvette with a $5 \mathrm{~mm}$ path length and measured in the 190-290 nm range.

\section{Transmission electron microscopy}

Transmission electron microscopy (TEM) peptide solution samples $(5 \mathrm{mg} / \mathrm{mL})$ were prepared at $25^{\circ} \mathrm{C}$ by dissolving lyophilized peptide powder in PBS (pH 7.4). After 48 hours, a micropipette was used to load $5 \mathrm{~mL}$ of this peptide solution to a carbon-coated copper grid. The excess solution was 
removed with a piece of filter paper. This peptide solution sample was dyed with $10 \mathrm{~mL}$ uranyl acetate for 30 seconds and dried overnight in a desiccator, and then bright-field images were taken with TEM (Philips Tecnai G2 F20, FEI Company, Hillsboro, OR, USA) operating at $200 \mathrm{kV}$.

\section{Rheometry assays}

Rheology experiments were performed on a $20 \mathrm{~mm}$ diameter $1^{\circ}$ stainless steel cone-controlled rheometer (Haake MARS, Thermo Fischer Scientific, Karlsruhe, Germany). Samples were dissolved in $20 \mathrm{mM} \mathrm{CaCl}_{2}$ or $\mathrm{NaCl}$ at a concentration of $10.0 \mathrm{mg} / \mathrm{mL}$, combining the D-RADA16-RGD peptide solution with $20 \mathrm{mM} \mathrm{CaCl}_{2}$ or $\mathrm{NaCl}$ at a volume ratio 1:1. These were stored at $4^{\circ} \mathrm{C}$ in a refrigerator overnight, and 150-200 $\mu \mathrm{L}$ samples were used for analysis at $25^{\circ} \mathrm{C}$.

\section{Scaffold assembly for the in vivo study}

Stock solutions and scaffolds were freshly prepared prior to surgeries. A $10 \mathrm{mg} / \mathrm{mL}$ (w/v) peptide stock solution was prepared by dissolving lyophilized peptide powder in sterile water. There were three groups for the in vivo study; details are as follows: Group 1: $10 \mathrm{mg} / \mathrm{mL}$ (w/v) D-RADA16-RGD + PBS (pH 7.4) (1:1), Group 2: 10 mg/mL (w/v) D-RADA16$\mathrm{RGD}+50 \mu \mathrm{g} / \mathrm{mL}(\mathrm{w} / \mathrm{v}) \mathrm{bFGF}(1: 1)$, and Group 3: PBS (pH 7.4). In Group 1, $10 \mathrm{mg} / \mathrm{mL}$ (w/v) D-RADA16-RGD solution was combined with PBS ( $\mathrm{pH} 7.4)$ at a volume ratio of 1:1, and the D-RADA16-RGD solution, after the stimulation with ionic PBS solution for 24 hours, self-assembled to form D-RADA16-RGD hydrogel scaffold for in vivo implantation. In Group 2, bFGF powder was dissolved in PBS ( $\mathrm{pH} 7.4$ ) to reach a concentration of $50 \mu \mathrm{g} / \mathrm{mL}(\mathrm{w} / \mathrm{v})$. Then, $10 \mathrm{mg} / \mathrm{mL}$ (w/v) D-RADA16-RGD solution was mixed with $50 \mu \mathrm{g} / \mathrm{mL}$ $(\mathrm{w} / \mathrm{v}) \mathrm{bFGF}$ at a volume ratio of 1:1. After 24 hours, bFGFincorporated D-RADA16-RGD hydrogel scaffold selfassembled and was used for in vivo implantation.

\section{Animal surgeries}

This experimental protocol was approved by the Institutional Animal Care and Use Committee of Chongqing Medical University of China, and Chinese national guidelines for the care and use of laboratory animals were applied. Female SD rats (weight ranging from 195 to $250 \mathrm{~g}$ ) were purchased from Laboratory Animal Center, Chongqing Medical University. The anesthesia for all the animals was induced by an intravenous administration of chloral hydrate $(10 \%$, $5.0-7.5 \mathrm{~mL} / \mathrm{kg}$ ). After exposure of the distal femoral condyle, a bone defect $2.5 \mathrm{~mm}$ in diameter and $3 \mathrm{~mm}$ in depth was created. The surgery was performed in both legs of the rats, and one defect was created in each femoral condyle.
The defects in the three groups were filled with the respective sample hydrogel material in a randomized manner $(n=9)$. After completely filling the femoral condyle defects, the superfluous gel was removed and soft tissues were closed layer by layer. Intramuscular injection of penicillin was used to prevent infection. After 8 and 12 weeks of implantation, three experimental groups (for 8 weeks) and six experimental groups (for 12 weeks) of SD rats were sacrificed using an overdose of anesthesia, and then the femoral condyles were harvested for microcomputed tomography (micro-CT) analysis and histological evaluation.

\section{Micro-CT analysis}

Three experimental groups were euthanized 8 weeks postoperation. After harvesting of the femoral condyles and removal of the surrounding soft tissues, the bone specimens were imaged in air using micro-CT (Viva CT40, Scanco Medical AG, Bassersdorf, Switzerland). The volume of new bone was derived from the CT images by delineating the areas of the contrast-enhanced regions of interest in the $\mathrm{X}, \mathrm{Y}$, and $\mathrm{Z}$ planes. Images were obtained by adjusting the micro-CT data window display to enhance the edge delineation of the new bone mass. The 2D images of the grafts were reconstructed using a middle-frequency kernel. The quantitative measurements of the new bone tissues were used to calculate bone volume per tissue volume (BV/TV), bone mean density (BMD), and trabecular thickness ( $\mathrm{Tb} \mathrm{Th}$ ).

\section{Histology}

The harvested bone specimens were fixed in 4\% paraformaldehyde solution for 2 days, subjected to decalcification, dehydrated in graded alcohol solutions, and embedded in paraffin. Samples were then sectioned (thickness $=5 \mu \mathrm{m}$ ) and stained with hematoxylin and eosin (H\&E).

\section{Statistics and data analysis}

All data were presented as the mean \pm standard deviation. For new bone formation measurement from micro-CT analysis, differences between groups were determined using an unpaired Student's $t$-test. The differences were considered significant if $P<0.05$.

\section{Results D-RADA 16-RGD peptide}

In this work, D-RADA16-RGD peptide powder was dissolved in deionized water till it reached a concentration of $10 \mathrm{mg} / \mathrm{mL}$. After 24 hours, D-RADA16-RGD peptide solution formed stable hydrogel (Figure 1A). D-RADA16-RGD peptide membrane was stained by Congo red dye, which has 


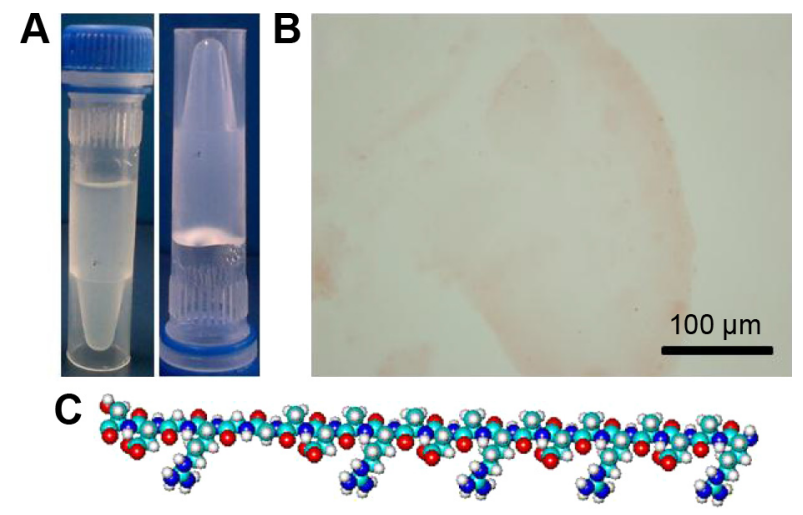

Figure I D-RADA I6-RGD peptide.

Notes: (A) 2\% D-RADA I6-RGD self-assembling peptides were dissolved in the deionized water. (B) Optical microscopy images of peptide membranes. The colorless membranous structure was formed in PBS ( $\mathrm{pH}$ 7.4) and transferred to a glass slide. D-RADAI6-RGD peptide membrane can be seen by the naked eyes when stained with Congo red. Scale bar: $100 \mu \mathrm{m}$. (C) The molecular model of d-EAKI6-RGD peptide.

Abbreviation: PBS, phosphate-buffered saline.

a preference for staining the $\beta$-sheet structures. Its transparent membrane structures were seen under phase-contrast microscope at $25^{\circ} \mathrm{C}$, and it can be seen even with the naked eyes. These results indicate that D-RADA16-RGD peptides are capable of producing stable membrane structures, providing the possibility to fabricate peptide scaffolds using RGD-modified D-form self-assembling peptides (Figure 1B). The molecular model of D-RADA16-RGD peptide had the peptide sequence Ac-(Arg-Ala-Asp-Ala-Arg-Ala-Asp-Ala) ${ }_{2}{ }^{-}$ Gly-Gly-Arg-Gly-Asp-Ser-CONH ${ }_{2}$ (Figure 1C).

\section{Secondary structural properties of peptide D-RADA I6-RGD}

The CD spectrum of peptide D-RADA16-RGD showed a maximum ellipticity at $218 \mathrm{~nm}$ and a minimum ellipticity at $198.5 \mathrm{~nm}$ at $25^{\circ} \mathrm{C}$, and the $\mathrm{CD}$ spectrum of peptide D-RADA16-RGD has a maximum and increased ellipticity at $218.5 \mathrm{~nm}$ and a minimum ellipticity at $199 \mathrm{~nm}$ at $37^{\circ} \mathrm{C}$. When raising the temperature to $60^{\circ} \mathrm{C}$, its $\mathrm{CD}$ spectrum showed a maximum but relatively reduced ellipticity at $218.5 \mathrm{~nm}$ and a minimum ellipticity at $200 \mathrm{~nm}$. Taken together, the peptide D-RADA16-RGD was able to form stable $\beta$-sheet secondary structure when the temperature ranged from $37^{\circ} \mathrm{C}$ to $60^{\circ} \mathrm{C}$ (Figure 2).

\section{Microstructures of D-RADA I6-RGD peptide nanofibers}

TEM measurements show that the peptide d-RADA16-RGD was able to self-assemble into nanofibers at $25^{\circ} \mathrm{C}$, and these nanofibers could be interwoven into a network structure

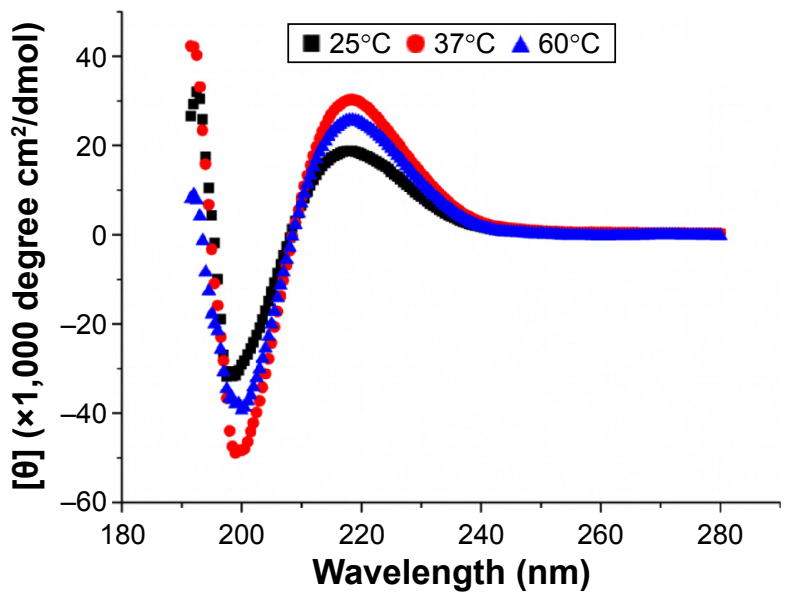

Figure $2 \mathrm{CD}$ spectra of peptide D-RADAI6-RGD at $25^{\circ} \mathrm{C}, 37^{\circ} \mathrm{C}$, and $60^{\circ} \mathrm{C}$. Abbreviations: $C D$, circular dichroism; $[\theta]$, ellipticity.

(Figure 3). The peptide D-RADA16-RGD nanofibers were approximately $145-650 \mathrm{~nm}$ in length and 5-30 $\mathrm{nm}$ in width, and the interwoven pore size ranged from 30 to $250 \mathrm{~nm}$.

\section{Rheological tests of peptide D-RADA I6- RGD}

Typical ionic $20 \mathrm{mM} \mathrm{CaCl}_{2}$ and $\mathrm{NaCl}$ solutions were selected to stimulate the self-assembly of peptide D-RADA16-RGD at $25^{\circ} \mathrm{C}$. Rheological experiments measure a storage modulus $\left(G^{\prime}\right)$ and a loss modulus $\left(G^{\prime \prime}\right)$ by evaluating the material's elastic response (rigidity) and material's viscous response, respectively, through varying frequencies of applied oscillatory stress. The storage modulus of peptide D-RADA16-RGD

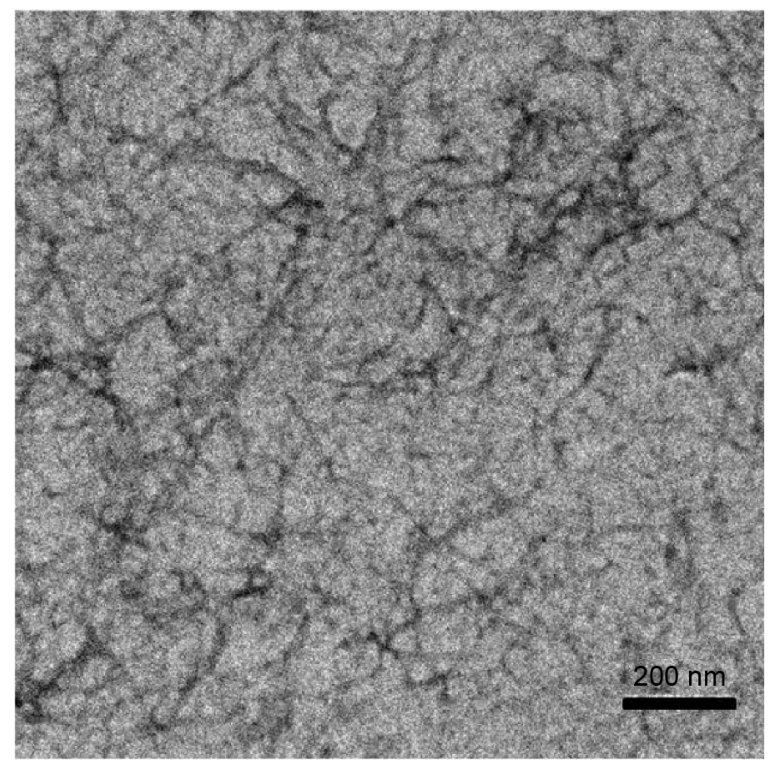

Figure 3 TEM image of $5 \mathrm{mg} / \mathrm{mL}$ D-RADA $6-R G D$ peptide nanofibers. Note: Scale bar: $200 \mathrm{~nm}$.

Abbreviation: TEM, transmission electron microscopy. 
is more than $9 \mathrm{~Pa}$ at the frequency of $10 \mathrm{rad} / \mathrm{s}$ in $20 \mathrm{mM}$ $\mathrm{NaCl}$, but the storage modulus of peptide D-RADA16-RGD is decreased to $7.3 \mathrm{~Pa}$ at the frequency of $10 \mathrm{rad} / \mathrm{s}$ in $20 \mathrm{mM}$ $\mathrm{CaCl}_{2}$ (Figure 4).

\section{Bone morphology change}

After 8 and 12 weeks of implantation, three experimental groups (for 8 weeks) and six experimental groups (for 12 weeks) of SD rats were sacrificed by an overdose of anesthesia and the femoral condyles were harvested for analysis. At 8 weeks, two experimental groups using D-RADA16-RGD hydrogel (Figure 5A) and bFGF-incorporated D-RADA16RGD hydrogel (Figure 5B) demonstrated significantly reduced areas of bone defects compared to PBS treatment (Figure 5C).

\section{Osteogenesis of various peptide hydrogels}

Figure 6 shows representative 2D reconstructions of the femoral condyles as created using micro-CT analysis of the explants at 8 weeks. D-RADA16-RGD hydrogel (Figure 6A) and bFGF-incorporated D-RADA16-RGD hydrogel (Figure 6B) treatments demonstrated obvious bone regeneration within the defect sites, with significantly reduced bone defects compared to PBS treatment (Figure 6C), in which dark-colored defect areas corresponding to reduced hard tissue are observed.

Quantification of the micro-CT analyses showed the BV/ $\mathrm{TV}, \mathrm{BMD}$, and $\mathrm{Tb}$ Th of each group (Figure $7 \mathrm{~A}-\mathrm{C}$ ). As can

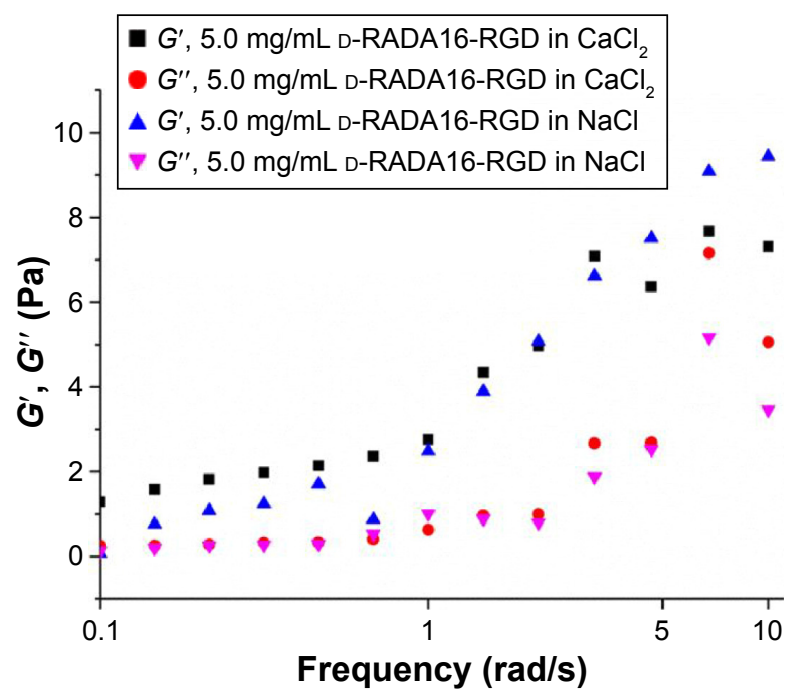

Figure 4 Rheological assays of the chiral peptides.

Notes: The rheological properties of $5.0 \mathrm{mg} / \mathrm{mL}$ D-RADA 16-RGD hydrogels in $20 \mathrm{mM} \mathrm{CaCl}$ and $\mathrm{NaCl}$ at $25^{\circ} \mathrm{C}$.

Abbreviations: $G^{\prime}$, the storage modulus; $G^{\prime \prime}$, the loss modulus. be seen in Figure 7A, the two experimental groups revealed significantly higher volumes of newly formed bone within the defect sites compared to the PBS treatment group $(P<0.05)$. When analyzing BV/TV of newly formed bone, no significant difference was found between D-RADA16-RGD hydrogel and bFGF-incorporated D-RADA16-RGD hydrogel treatment $(P>0.05)$. As shown in Figure 7B, D-RADA16-RGD hydrogel and bFGF-incorporated D-RADA16-RGD hydrogel treatment were able to produce substantially higher BMD of newly formed bone within the defect area than PBS treatment $(P<0.05)$. When analyzing BMD of newly formed bone, there was also no significant difference between d-RADA16RGD hydrogel and bFGF-incorporated D-RADA16-RGD hydrogel treatment $(P>0.05)$. As seen in Figure 7C, only D-RADA16-RGD hydrogel treatment demonstrated significantly increased $\mathrm{Tb}$ Th of newly formed bone within the defect compared to PBS treatment $(P<0.05)$.

\section{Histological analyses}

A qualitative histological assessment confirmed the results from micro-CT measurements. At 8 weeks, there were obvious newly formed bone tissues within the defect area when using D-RADA16-RGD hydrogel (Figure 8A) and bFGF-incorporated D-RADA16-RGD hydrogel (Figure 8B) when compared to PBS treatment (Figure 8C). In addition, newly formed bone within the defect area was significantly increased after 12 weeks, and the bone defects were almost completely filled with newly formed bone when treated with D-RADA16-RGD hydrogel (Figure 8D) and bFGFincorporated D-RADA16-RGD hydrogel (Figure 8E). However, large bone defects remained after PBS treatment at 12 weeks (Figure 8F).

\section{Discussion}

Amino acids can be divided into D- and L-forms, but molecular evolution in nature has a preference for the L-form amino acids. However, peptide bonds formed by D-amino acids have higher stability than that of L-amino acids, as evidenced by the proteases being able to degrade L-form peptide bonds but unable to degrade D-form peptide bonds. ${ }^{32,33}$ Indeed, many L-form self-assembling peptide hydrogel scaffolds have been found to hold significant promise in cell culture and tissue regeneration. For instance, RADA16-I peptideformed hydrogel scaffolds substantially promote neurite outgrowth, the repair of optical neurons, wound healing, and cardiac repair, ${ }^{19,34-37}$ while KLDL12 peptide hydrogel scaffolds contribute favorably to chondrocyte culture and cartilage regeneration..$^{13,38}$ 

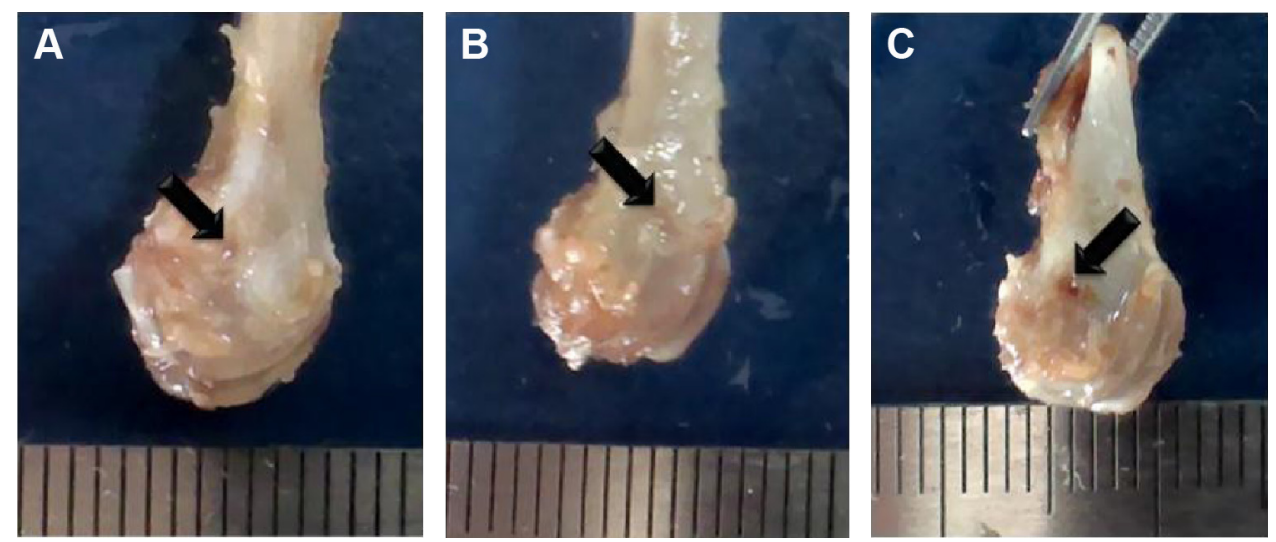

Figure 5 Various peptide hydrogels enhance bone healing and bone morphology change at 8 weeks.

Notes: (A) D-RADA I6-RGD hydrogel, (B) bFGF-incorporated D-RADAI6-RGD hydrogel, and (C) PBS (pH 7.4). Black arrow: bone defect. Abbreviations: PBS, phosphate-buffered saline; bFGF, basic fibroblast growth factor.

Previous studies have reported that d-EAK16 peptides could form stable hydrogel structures, which benefits hemostasis and cell culture. ${ }^{39}$ It will be very interesting and meaningful to investigate whether D-form and functionalized D-form self-assembling peptides can form stable 3D material structures and have the capability of promoting bone healing. Thus, our work focuses on the structural features and the osteogenic capability of D-RADA16-RGD peptide hydrogels with or without bFGF. To our knowledge, this is the first study to use RGD-modified D-form peptide hydrogel scaffolds to enhance bone regeneration.

D-RADA16-RGD peptide solution can form stable hydrogel structure even in deionized water. Previous studies have shown that the stimulus of ionic solution (eg, $\mathrm{Ca}^{2+}$ and $\mathrm{Na}^{+}$) can accelerate the rate of generation of hydrogels. ${ }^{12}$ Congo red staining demonstrated that the D-RADA16-RGD peptide solution was able to spontaneously assemble into durable hydrogel membranes at $25^{\circ} \mathrm{C}$ (Figure 1). They could also give rise to stable $\beta$-sheet secondary structure, as evidenced by $\mathrm{CD}$ spectra analysis. The increase in temperature (ranging from $25^{\circ} \mathrm{C}$ to $60^{\circ} \mathrm{C}$ ) also had no obvious influence on the secondary structure of D-RADA16-RGD peptide (Figure 2). TEM measurements demonstrated that the length and width of D-RADA16-RGD nanofibers were at the nanoscale level, especially the pore size of interwoven networks that range from 30 to $250 \mathrm{~nm}$, which have favorable influence on cell infiltration and dwelling (Figure 3).

In our unpublished data, the frequency $G^{\prime}$ of peptide D-RADA16 in $20 \mathrm{mM} \mathrm{NaCl}$ was found to be higher than that in $20 \mathrm{mM} \mathrm{CaCl}_{2}$. The frequency $G^{\prime}$ of peptide D-RADA16 was more than $60 \mathrm{~Pa}$ at the frequency of $10 \mathrm{rad} / \mathrm{s}$ in $20 \mathrm{mM}$ $\mathrm{NaCl}$, while the frequency $G^{\prime}$ of peptide D-RADA16 was reduced to $13.4 \mathrm{~Pa}$ at the frequency of $10 \mathrm{rad} / \mathrm{s}$ in $20 \mathrm{mM}$ $\mathrm{CaCl}_{2}$ (submitted data). When comparing the rheological property of peptide D-RADA $16(5 \mathrm{mg} / \mathrm{mL})$ and D-RADA16$\mathrm{RGD}(5 \mathrm{mg} / \mathrm{mL})$ self-assembly in $20 \mathrm{mM} \mathrm{CaCl}_{2}$ and $\mathrm{NaCl}$, the frequency $G^{\prime}$ of D-RADA 16 hydrogel was greater than that of D-RADA16-RGD hydrogel at the frequency of $10 \mathrm{rad} / \mathrm{s}$. These results revealed that the structural stability of 3D networks of peptide D-RADA16 was better than that of
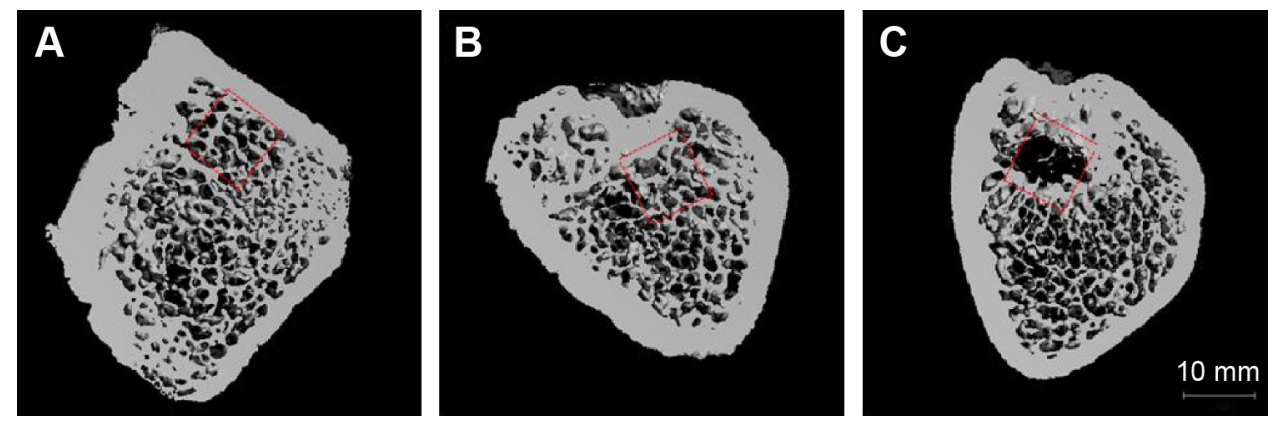

Figure 6 Osteogenic observation of various peptide hydrogels 8 weeks after implantation.

Notes: The morphology of the explanted femoral condyles undergoes 2D reconstructed micro-CT images, (A) D-RADAI6-RGD hydrogel, (B) bFGF-incorporated D-RADA 6-RGD hydrogel, and (C) PBS (pH 7.4). Cylinder-shaped defects are depicted in red. Scale bar: $10 \mathrm{~mm}$.

Abbreviations: PBS, phosphate-buffered saline; 2D, two-dimensional; micro-CT, micro computed tomography; bFGF, basic fibroblast growth factor. 

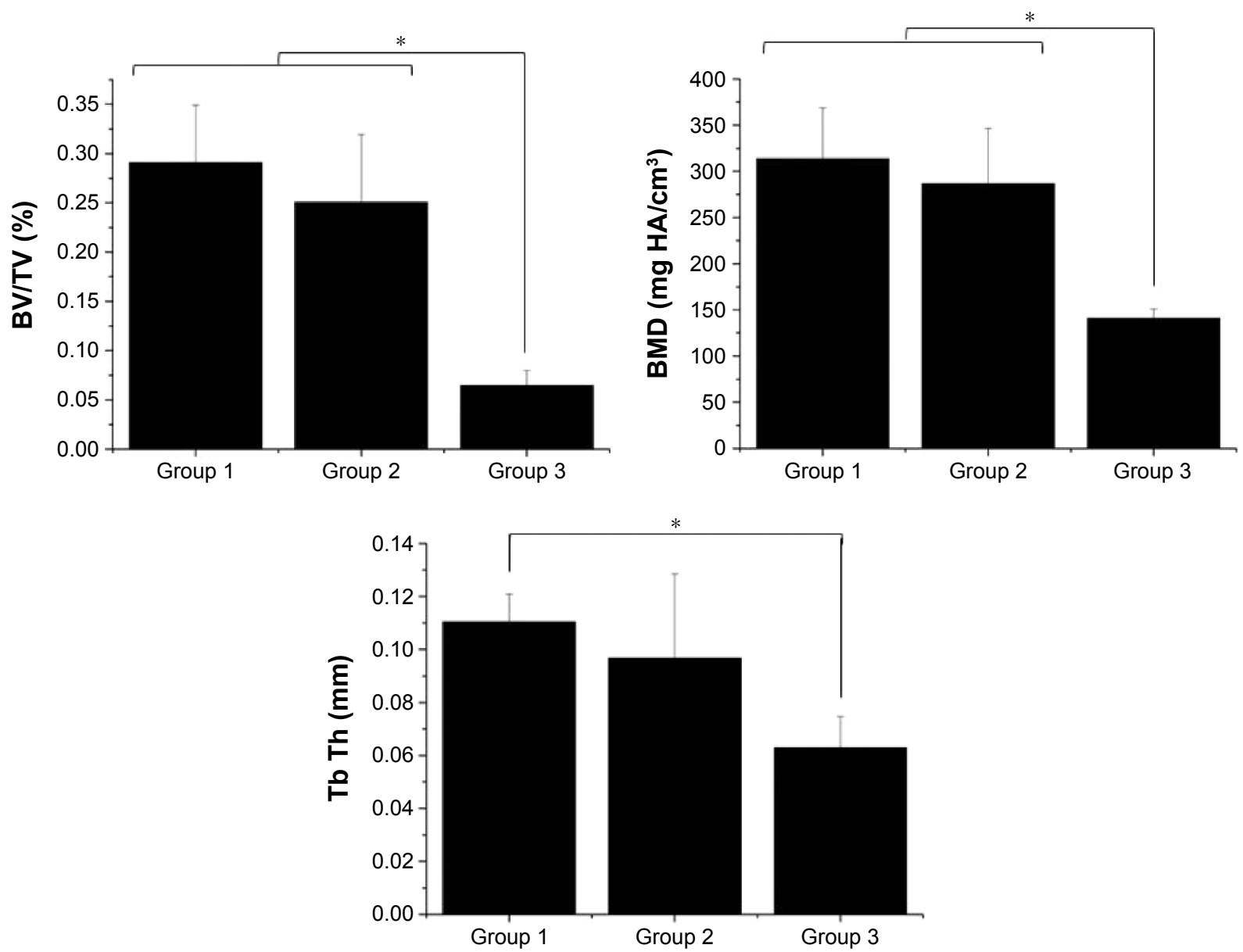

Figure 7 Osteogenic observation of various peptide hydrogels 8 weeks after implantation.

Notes: Morphometric analysis of (A) BV/TV, (B) BMD, and (C) Tb Th, Group I: D-RADAI6-RGD hydrogel + PBS (pH 7.4), Group 2: D-RADAI6-RGD hydrogel + bFGF, and Group 3: PBS ( $\mathrm{PH} 7.4)$. There was a significant difference between groups $(* P<0.05)$.

Abbreviations: PBS, phosphate-buffered saline; bFGF, basic fibroblast growth factor; BV/TV, bone volume per tissue volume; BMD, bone mean density; Tb Th, trabecular thickness.
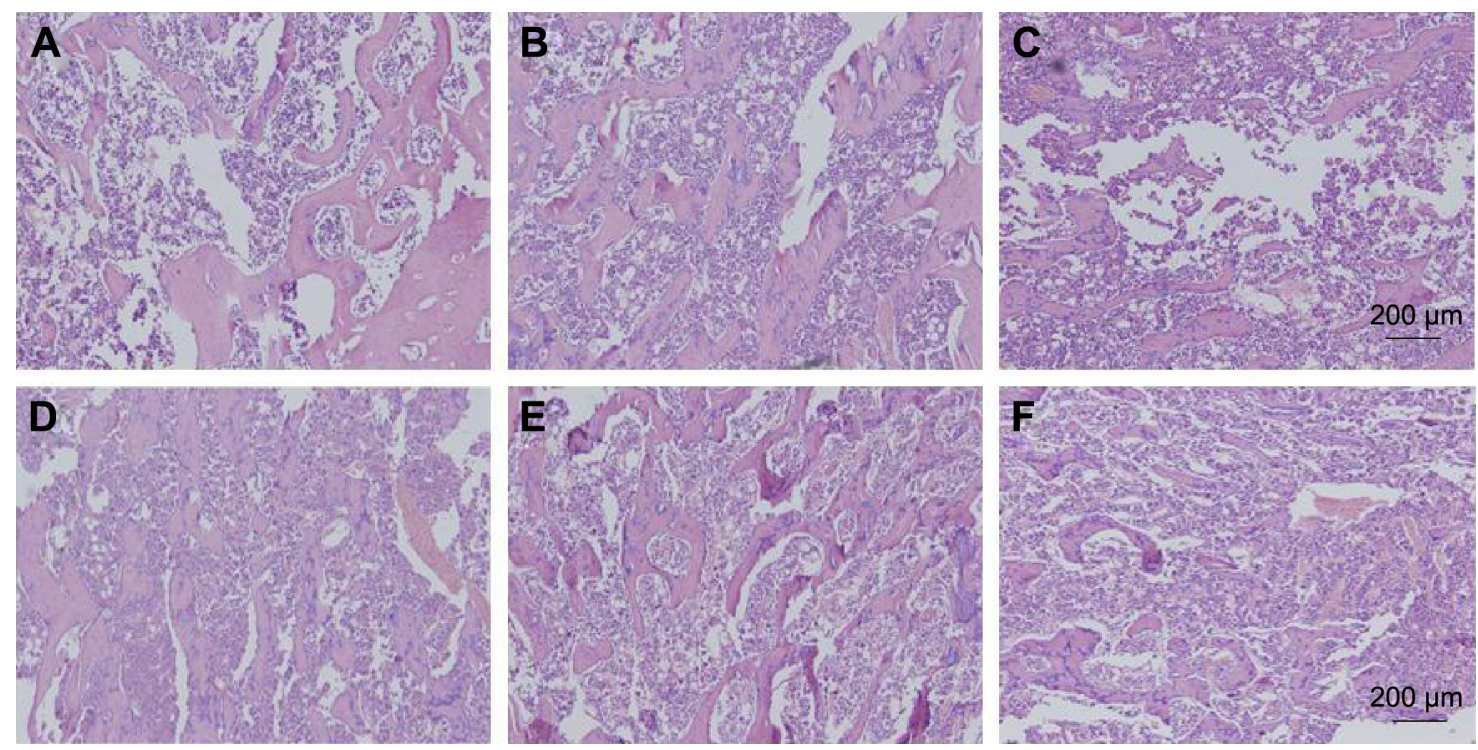

Figure 8 Histological analyses of the explants 8 weeks (A-C) and 12 weeks (D-F) after implantation.

Notes: Histological sections of the rat femoral condyle defects and stained by H\&E. (A, D) D-RADA I6-RGD hydrogel, (B, E) bFGF-incorporated D-RADA I6-RGD hydrogel, and (C, F) PBS (pH 7.4). Scale bar: $200 \mu \mathrm{m}$, magnification: 100x.

Abbreviations: bFGF, basic fibroblast growth factor; H\&E, hematoxylin and eosin; PBS, phosphate-buffered saline. 
peptide D-RADA16-RGD due to the addition of RGD, possibly because the addition of RGD had a negative influence on peptide self-assembly and formed physical hindrances (Figure 4). Furthermore, D-RADA16-RGD hydrogel and D-RADA16 hydrogel were both found to have reduced structural stability of 3D networks with increasing ionic strength ranging from $20 \mathrm{mM} \mathrm{NaCl}$ to $20 \mathrm{mM} \mathrm{CaCl}_{2}$, possibly because there was some dissolution of peptide hydrogels.

Current studies mainly focus on L-form peptide nanofibers for bone healing. For instance, mesenchymal stem cells were cultured on RADA16-I self-assembling peptide hydrogels, resulting in good osteogenic differentiation and mineralized ECMs. ${ }^{40,41}$ RADA16-I nanofiber scaffolds were found to promote the formation of bony bridges and mature bone tissue with cortical bone medullary cavities when repairing the calvaria bone defects of the mouse model. ${ }^{42}$ In addition, after being implanted into the periosteum of the bilateral ilia in the athymic mice model, self-assembly peptide/DBM composite scaffolds were found to significantly increase the volume of newly formed bone tissues compared to DBM treatment. ${ }^{43}$ These composite material scaffolds were also able to notably promote the bone healing of femur defects in a goat model when compared to DBM treatment. ${ }^{44}$

To test the osteogenic capacity of D-form self-assembly peptide with RGD functionalization, D-RADA16-RGD hydrogel and bFGF-incorporated D-RADA16-RGD hydrogel were used to fill the bone defect of the SD rat femoral condyle. Bone morphology change in harvested femoral condyles, and BV/TV, BMD, and $\mathrm{Tb}$ Th analysis of newly formed bone tissues as well as their H\&E staining have revealed that D-RADA16-RGD hydrogel scaffolds have a significantly favorable influence on the healing of bone defects in the SD rat model (Figures 5-8). However, no significant difference was found in the promotion of bone healing between D-RADA16-RGD hydrogel and bFGFincorporated D-RADA16-RGD hydrogel treatments because D-RADA16-RGD hydrogel has relatively weak structural stability of 3D networks for controlled release of bFGF (Figure 3). Therefore, it is necessary to combine D-RADA16-RGD hydrogel with other materials with good mechanical stability to fabricate composite scaffolds for the storage and release of growth factors. As one of the heparin-binding proteins, bFGF mainly accounts for the cell proliferation and differentiation through binding to its corresponding receptors. It is believed that modifying peptide-based scaffold materials with heparan sulfate proteoglycans can substantially increase the local concentration of bFGF for bone healing through their electrostatic interactions. ${ }^{45}$ Furthermore, D-RADA16-RGD hydrogel and bFGF-incorporated D-RADA16-RGD hydrogel treatments have revealed its significant potential in bone repair, but the detailed mechanism is not clear. More experiments are needed to clarify the related mechanism.

In addition, there is an emerging agreement that designer biomaterial scaffolds aim at developing an ideal microenvironment for stimulating the body's innate powers of organization and self-repair, rather than directly reconstructing tissue or organs ex vivo for replacing damaged tissues. ${ }^{46}$ The design and fabrication of biomaterial scaffolds for biomedical applications should be intended to mimic the microstructure of natural ECMs and induce the self-repair and regulatory mechanisms of damaged tissues. During these complex selfrepair processes, it is very important to optimize the symbiosis of material scaffolds, cells, and signal molecules. ${ }^{12}$

\section{Conclusion}

D-RADA16-RGD peptide solution can not only form stable hydrogel structures, but also have an important potential in promoting bone repair of condyle defects of female SD rats. On the basis of the bone morphology change, $2 \mathrm{D}$ reconstructions of micro-CT, quantification of the micro-CT analyses (ie, BV/TV, BMD, and Tb Th), as well as histological analyses, D-RADA16-RGD peptide hydrogels were found to obviously promote bone regeneration. However, these hydrogel scaffolds may not allow the effective and slow release of growth factors for bone healing due to their relatively weak structural stability of 3D networks. It is believed that combining D-RADA16-RGD hydrogel with other materials with good mechanical force can play an increasingly significant role in the fabrication of composite scaffolds for the slow release of signal molecules, especially for the regeneration of large bone defects and load-bearing bone defects.

\section{Acknowledgment}

This research was supported by the National Natural Science Foundation of China (NSFC, 81472057).

\section{Disclosure}

The authors report no conflicts of interest in this work.

\section{References}

1. Dimitriou R, Jones E, McGonagle D, et al. Bone regeneration: current concepts and future directions. BMC Med. 2011;9:66.

2. Soucacos PN, Kokkalis ZT, Piagkou M, et al. Vascularized bone grafts for the management of skeletal defects in orthopaedic trauma and reconstructive surgery. Injury. 2013;44(Suppl 1):S70-S75.

3. He B, Yuan X, Wu J, et al. Self-assembling peptide nanofiber scaffolds for bone tissue engineering. Sci Adv Mater. 2015;7:1221-1232. 
4. Long T, Zhu Z, Awad HA, et al. The effect of mesenchymal stem cell sheets on structural allograft healing of critical sized femoral defects in mice. Biomaterials. 2014;35:2752-2759.

5. Qi M, Hu J, Li J, et al. Effect of zoledronate acid treatment on osseointegration and fixation of implants in autologous iliac bone grafts in ovariectomized rabbits. Bone. 2012;50:119-127.

6. De Long WG Jr, Einhorn TA, et al. Bone grafts and bone graft substitutes in orthopaedic trauma surgery. A critical analysis. J Bone Joint Surg Am. 2007;89:649-658.

7. Rice CM, Mallam EA, Whone AL, et al. Safety and feasibility of autologous bone marrow cellular therapy in relapsing-progressive multiple sclerosis. Clin Pharmacol Ther. 2010;87:679-685.

8. Lee SS, Huang BJ, Kaltz SR, et al. Bone regeneration with low dose BMP-2 amplified by biomimetic supramolecular nanofibers within collagen scaffolds. Biomaterials. 2013;34:452-459.

9. Bose S, Roy M, Bandyopadhyay A. Recent advances in bone tissue engineering scaffolds. Trends Biotechnol. 2012;30:546-554.

10. Mourino V, Boccaccini AR. Bone tissue engineering therapeutics: controlled drug delivery in three-dimensional scaffolds. J R Soc Interface. 2010;7:209-227.

11. Kim SH, Hur W, Kim JE, et al. Self-assembling peptide nanofibers coupled with neuropeptide substance $\mathrm{P}$ for bone tissue engineering. Tissue Eng Part A. 2015;21:1237-1246.

12. He B, Yuan X, Zhou A, et al. Designer functionalised self-assembling peptide nanofibre scaffolds for cartilage tissue engineering. Expert Rev Mol Med. 2014;16:e12.

13. Kisiday J, Jin M, Kurz B, et al. Self-assembling peptide hydrogel fosters chondrocyte extracellular matrix production and cell division: implications for cartilage tissue repair. Proc Natl Acad Sci U S A. 2002;99: 9996-10001.

14. Li A, Hokugo A, Yalom A, et al. A bioengineered peripheral nerve construct using aligned peptide amphiphile nanofibers. Biomaterials. 2014; 35:8780-8790.

15. He B, Yuan X, Jiang D. Molecular self-assembly guides the fabrication of peptide nanofiber scaffolds for nerve repair. $R S C A d v$. 2014;4: 23610-23621.

16. Yuan X, He B, Lv Z, et al. Fabrication of self-assembling peptide nanofiber hydrogels for myocardial repair. RSC Adv. 2014;4:53801-53811.

17. Segers VF, Lee RT. Biomaterials to enhance stem cell function in the heart. Circ Res. 2011;109:910-922.

18. Loo Y, Wong YC, Cai EZ, et al. Ultrashort peptide nanofibrous hydrogels for the acceleration of healing of burn wounds. Biomaterials. 2014; 35:4805-4814

19. Schneider A, Garlick JA, Egles C. Self-assembling peptide nanofiber scaffolds accelerate wound healing. PLoS One. 2008;3:e1410.

20. Hauser CA, Zhang S. Designer self-assembling peptide nanofiber biological materials. Chem Soc Rev. 2010;39:2780-2790.

21. Koutsopoulos S, Unsworth LD, Nagai Y, et al. Controlled release of functional proteins through designer self-assembling peptide nanofiber hydrogel scaffold. Proc Natl Acad Sci U S A. 2009;106:4623-4628.

22. Luo Z, Wang S, Zhang S. Fabrication of self-assembling D-form peptide nanofiber scaffold d-EAK16 for rapid hemostasis. Biomaterials. 2011; 32:2013-2020.

23. Woerly S, Pinet E, de Robertis L, et al. Spinal cord repair with PHPMA hydrogel containing RGD peptides (NeuroGel). Biomaterials. 2001;22: $1095 \mathrm{c} 1111$.

24. Graf J, Ogle RC, Robey FA, et al. A pentapeptide from the laminin B1 chain mediates cell adhesion and binds the 67,000 laminin receptor. Biochemistry. 1987;26:6896-6900.

25. Ruoslahti E, Pierschbacher MD. Arg-Gly-Asp: a versatile cell recognition signal. Cell. 1986;44:517-518.
26. Smith Callahan LA, Childers EP, Bernard SL, et al. Maximizing phenotype constraint and extracellular matrix production in primary human chondrocytes using arginine-glycine-aspartate concentration gradient hydrogels. Acta Biomater. 2013;9:7420-7428.

27. Potter W, Kalil RE, Kao WJ. Biomimetic material systems for neural progenitor cell-based therapy. Front Biosci. 2008;13:806-821.

28. Gelain F, Unsworth LD, Zhang S. Slow and sustained release of active cytokines from self-assembling peptide scaffolds. JControl Release. 2010; 145:231-239.

29. Carano RA, Filvaroff EH. Angiogenesis and bone repair. Drug Discov Today. 2003;8:980-989.

30. Luong LN, Ramaswamy J, Kohn DH. Effects of osteogenic growth factors on bone marrow stromal cell differentiation in a mineral-based delivery system. Biomaterials. 2012;33:283-294.

31. Hosseinkhani H, Hosseinkhani M, Tian F, et al. Osteogenic differentiation of mesenchymal stem cells in self-assembled peptide-amphiphile nanofibers. Biomaterials. 2006;27:4079-4086.

32. Zhang S, Holmes T, Lockshin C, et al. Spontaneous assembly of a selfcomplementary oligopeptide to form a stable macroscopic membrane. Proc Natl Acad Sci U S A. 1993;90:3334-3338.

33. Luo Z, Zhao X, Zhang S. Structural dynamic of a self-assembling peptide d-EAK16 made of only D-amino acids. PLoS One. 2008;3:e2364.

34. Holmes TC, de Lacalle S, Su X, et al. Extensive neurite outgrowth and active synapse formation on self-assembling peptide scaffolds. Proc Natl Acad Sci U S A. 2000;97:6728-6733.

35. Ellis-Behnke RG, Liang YX, You SW, et al. Nano neuro knitting: peptide nanofiber scaffold for brain repair and axon regeneration with functional return of vision. Proc Natl Acad Sci U S A. 2006;103:5054-5059.

36. Guo HD, Cui GH, Wang HJ, et al. Transplantation of marrow-derived cardiac stem cells carried in designer self-assembling peptide nanofibers improves cardiac function after myocardial infarction. Biochem Biophys Res Commun. 2010;399:42-48.

37. Hosseinkhani H, Hong PD, Yu DS. Self-assembled proteins and peptides for regenerative medicine. Chem Rev. 2013;113:4837-4861.

38. Liu J, Song H, Zhang L, et al. Self-assembly-peptide hydrogels as tissueengineering scaffolds for three-dimensional culture of chondrocytes in vitro. Macromol Biosci. 2010;10:1164-1170.

39. Luo Z, Yue Y, Zhang Y, et al. Designer D-form self-assembling peptide nanofiber scaffolds for 3-dimensional cell cultures. Biomaterials. 2013; 34:4902-4913.

40. Hamada K, Hirose M, Yamashita T, et al. Spatial distribution of mineralized bone matrix produced by marrow mesenchymal stem cells in self-assembling peptide hydrogel scaffold. J Biomed Mater Res A. 2008; $84: 128-136$

41. Chen J, Shi ZD, Ji X, et al. Enhanced osteogenesis of human mesenchymal stem cells by periodic heat shock in self-assembling peptide hydrogel. Tissue Eng Part A. 2013;19:716-728.

42. Misawa H, Kobayashi N, Soto-Gutierrez A, et al. PuraMatrix facilitates bone regeneration in bone defects of calvaria in mice. Cell Transplant. 2006;15:903-910.

43. Hou T, Li Z, Luo F, et al. A composite demineralized bone matrix - self assembling peptide scaffold for enhancing cell and growth factor activity in bone marrow. Biomaterials. 2014;35:5689-5699.

44. Li Z, Hou T, Luo F, et al. Bone marrow enriched graft, modified by self-assembly peptide, repairs critically-sized femur defects in goats. Int Orthop. 2014;38(11):2391-2398.

45. Dvir T, Timko BP, Kohane DS, et al. Nanotechnological strategies for engineering complex tissues. Nat Nanotechnol. 2011;6:13-22.

46. Place ES, Evans ND, Stevens MM. Complexity in biomaterials for tissue engineering. Nat Mater. 2009;8:457-470 


\section{Publish your work in this journal}

Drug Design, Development and Therapy is an international, peerreviewed open-access journal that spans the spectrum of drug design and development through to clinical applications. Clinical outcomes, patient safety, and programs for the development and effective, safe, and sustained use of medicines are a feature of the journal, which

has also been accepted for indexing on PubMed Central. The manuscript management system is completely online and includes a very quick and fair peer-review system, which is all easy to use. Visit http://www.dovepress.com/testimonials.php to read real quotes from published authors.

Submit your manuscript here: http://www.dovepress.com/drug-design-development-and-therapy-journal 